\title{
El Estado y los megaproyectos turísticos El caso de Cabo Pulmo, Baja California Sur, México
}

\author{
Mariel Verónica Massé Magaña* \\ Celia Guzmán Hernández \\ Universidad Autónoma del Estado de México
}

\section{Resumen}

El Estado nacional fortalece los intereses económicos de las clases dominantes burguesas por medio del poder político. Desde esa perspectiva, se contextualiza el surgimiento del turismo en México como un objetivo económico para favorecer las inversiones internacionales, lo que históricamente ha implicado la construcción de megaproyectos turísticos para atender a un turismo masificado de élite. Esto ha redundado en beneficios económicos para los consorcios hoteleros internacionales, pero ha provocado la degradación socioambiental debido al consumo desmedido de los recursos naturales, además del despojo de tierras de los ejidatarios o comuneros locales. Se analizan las relaciones entre el Estado y la empresa española Hansa Urbana Investments más allá de lo formal, en la autorización otorgada para la construcción del megaproyecto turístico Cabo Cortés, propuesto en un área adyacente al Parque Nacional Cabo Pulmo; donde el Estado ajustó sus políticas por la presión de las instancias internacionales que determinan el modelo de turismo hegemónico para privatizar el territorio en favor de los inversionistas. La investigación se sustenta en la propuesta teórica de Jaime Osorio y considera el papel del Estado, el poder político y las relaciones sociales para explicar este problema. El proceso metodológico integró entrevistas en profundidad a informantes clave, lo que dio como resultado la comprobación de la conjetura señalada y que guía este estudio. Finalmente se concluye que en la expansión del capitalismo predominan las inversiones de megaproyectos de sol y playa, siendo los inversores quienes, al tener el poder económico, controlan el mercado turístico internacional y las relaciones de poder en el Estado. Sin embargo, en la actualidad la lucha social de la comunidad local de Cabo Pulmo surge para impedir las afectaciones al patrimonio natural, la exclusión, el desplazamiento de la población y el despojo de su territorio.

\section{Palabras clave}

Megaproyectos turísticos, Estado, poder político, Cabo Pulmo.

Recibido: 19/05/2015 · Aceptado: 05/06/2015

*Correo electrónico: Imari.masse@hotmail.com, cgh131060@yahoo.com.mx 


\title{
The State and the Touristic Megaprojects The case of Cabo Pulmo, Baja California Sur, Mexico
}

\author{
Mariel Verónica Massé Magaña* \\ Celia Guzmán Hernández \\ Universidad Autónoma del Estado de México
}

\begin{abstract}
The National State strengthens the economic interests of the bourgeois ruling classes through political power. From that perspective, the emergence of tourism in Mexico is contextualized as an economic aim of promoting international investment, which has historically involved the construction of tourist megaprojects of great magnitude to attend a crowded elite tourism. This has resulted in economic benefits for international hotel groups, but has led to the socio-environmental degradation due to excessive consumption of natural resources besides the dispossession of land from landowners and local villagers. With the above relations between the state and the Spanish company Hansa Urbana Investments beyond formal, in the authorization granted to build the tourist megaproject Cabo Cortés proposed in the adjacent Cabo Pulmo National Park are analyzed; where the government adjusts its policies under pressure from international bodies that determine the hegemonic model of tourism to privatize the territory for investors. The research is based on the theoretical proposal of Jaime Osorio considering the role of the state, political power and social relations to explain this problem. The methodology integrated in-depth interviews with key informants, resulting in checking the aforementioned conjecture that guide this study. Finally we conclude that the expansion of capitalism mega investments sun and sand predominate, with investors who have the economic power and manage the international tourism market and the relations of power in the state. However currently the social struggle of the local community of Cabo Pulmo emerges as front against the effects of natural heritage, exclusion, displacement and dispossession of their territory.
\end{abstract}

\section{KEY WORDS}

Tourist megaprojects, State, political power, Cabo Pulmo.

*E-mail: lmari.masse@hotmail.com, cgh131060@yahoo.com.mx 


\section{Introducción}

Desde sus inicios, el turismo en México implementó un modelo importado llamado de sol y playa para el cual fue necesario crear una infraestructura masiva a fin de lograr la mayor captación de visitantes y con ello una alta derrama económica. Hoy en día el gobierno sigue apostando por desarrollos turísticos de esta clase con la promesa de mejorar la calidad de vida de las comunidades, pero lo que ocurre es una degradación considerable de los ecosistemas debido al alto consumo de recursos naturales y al volumen de contaminantes que se generan, lo cual ha producido inconformidad en las poblaciones locales. Debido a esto, hace falta un análisis y una crítica del caso de Cabo Cortés, entre otros ejemplos, con la finalidad de replantear el manejo estatal y local de los ecosistemas protegidos y de los que no cuentan con alguna protección especial, así como de las relaciones que surgen entre los operadores internacionales de la actividad turística y el Estado. En una de sus facetas, este último se rige por una política cuyo fin es el bien común, pero por otra actúa en favor de intereses privados. La lucha social por la conservación de ecosistemas para evitar la pérdida de paisajes naturales es el principal factor de oposición contra la privatización, a la que se aúna al despojo, la exclusión y el desplazamiento de las poblaciones locales.

Aquí es donde las categorías de análisis de investigación que propone Jaime Osorio: Estado, poder político y relaciones sociales, ayudaron a explicar cómo el poder económico apoyado por el Estado impone las políticas turísticas internacionales, controla la economía mundial y determina los modelos por los cuales ha de operarse la actividad turística, que busca en los países periféricos la oportunidad para llevar a cabo sus proyectos e intereses privados. Para ello, a través de actos ilegítimos, establece relaciones económico-políticas con los aparatos de Estado y logra filtrar sus intereses y la continua reproducción del modelo capitalista.

La propuesta metodológica se apoyó en una investigación documental y de campo. Con ambas se recopiló la información que comprueba la articulación entre el Estado, el poder político y las relaciones sociales que se establecen entre los funcionarios o empleados estatales, servidores públicos, sociedad civil y los empresarios en favor de los megaproyectos turísticos. 
Asimismo, tanto los artículos científicos como las notas periodísticas presentan diversos casos de desarrollos turísticos que han causado daños notables en distintos litorales mexicanos. Después, en la investigación de campo se aplicaron entrevistas a profundidad a informantes clave pertenecientes a distintos sectores sociales: académico-investigativo, periodístico y organizaciones no gubernamentales (ONG).

\section{Antecedentes: el nacimiento del turismo internacional en México}

De 1946 a 1952 la economía mexicana giraba en torno del sector primario, y en las zonas rurales predominaban las economías de autoconsumo, por lo que la actividad de exportación era muy reducida; el sector secundario se desarrollaba mediante la actividad artesanal y algunas manufacturas; y en el terciario había escasos servicios para la comercialización debido a una infraestructura carretera casi inexistente, además de un sistema ferroviario muy devastado. Este contexto sectorial originó un país con grandes contrastes sociales que declaraba el discurso de la modernización, creando necesidades, entre ellas los denominados satisfactores turísticos, pero vinculados al consumo y a la generación de plusvalía, buscando desde entonces modificar los espacios naturales por medio de megaproyectos que lesionan el medio ambiente natural y social.

En esos años, el Estado estructuraba políticas y normatividades de fomento a las empresas del sector secundario y desplazaba al rural con la disminución de presupuesto. Sin embargo, esto no obedecía a la condición productiva del país, sino a la presión de las naciones imperialistas que se apropiaban con gran facilidad de los medios de producción (territorio, recursos naturales), y que eran favorecidos por el proteccionismo aduanero; de tal forma que México representaba un paraíso económico.

En el contexto internacional, el turismo beneficiaba a países desarrollados como Estados Unidos, Francia y Alemania, y era apoyado por organizaciones internacionales como la Organización Mundial del Turismo (омт), el Fondo Monetario Internacional (FMI), el Banco Mundial (BM), la Organización de las Naciones Unidas (onu) y la Organización de las Naciones Unidas para la Educación, la Ciencia y la Cultura (Unesco, por sus siglas en inglés). Una vez reconocidos los ingresos que dejaba esta actividad surgió la idea de que también los 
países en vías de desarrollo obtuvieran rendimientos del turismo. Así, se invitó a las naciones periféricas a integrar el turismo como instrumento económico prioritario y recibir capitales extranjeros, con la promesa de que los beneficios que este generara se reflejarían en su economía mediante la disminución de deudas y pobreza. Esta apertura al turismo internacional por influencia de los organismos internacionales de turismo y las firmas multinacionales modificó ciertos aspectos en las políticas económicas estatales para poder iniciar grandes proyectos que satisficieran la alta demanda de visitantes, anteponiendo el turismo extranjero sobre el nacional y desintegrando a su vez los sistemas de referencias nacionales a partir de las decisiones políticas centrales (Lanfant, 1980). En estas condiciones empezó un aprovechamiento irracional de los litorales mexicanos bajo el concepto importado de sol y playa, con enclaves inmobiliarios y hoteles de lujo en centros turísticos tradicionales como: Acapulco, Mazatlán, Puerto Vallarta, etcétera.

Desde entonces México integró el turismo como un pilar económico prioritario, por lo que instituyó formalmente a la Secretaría de Turismo (Sectur) y al Fondo Nacional de Fomento al Turismo (Fonatur), que se encargarían de crear desarrollos sustentables y fomentar la compra-venta de terrenos o concesiones para la inversión turística. Estos organismos impulsaron cinco destinos de playa: Loreto, Nopoló, Litibú, Costa del Pacífico y Cancún, llamados centros integralmente planeados (CIP), los cuales tenían como objetivo ser motores de desarrollo turístico donde no existía un crecimiento económico, con el fin de atender a un turismo masificado, por lo que se les dotó de una amplia infraestructura mediante la inversión de capitales privados, principalmente extranjeros. Alejandro Olivera Bonilla dice al respecto:

Han sido declarados fracasados e incompatibles con la realidad que vive y afronta el país en términos económicos; los cuales tal vez, décadas atrás, tuvieron cierto éxito. Posteriormente se dio una crisis en el sector inmobiliario de más de una década, lo cual frenó su crecimiento, por lo tanto es un error seguir apostando y promoviendo estos desarrollos en ecosistemas frágiles costeros. Muchos de los cip han quedado sin terminar por falta de recursos económicos del Estado; sin embargo, ello no ha evitado la pérdida de ecosistemas, el desplazamiento de las comunidades locales, además de pobreza, contaminación y desigualdad social. México solo pierde sus entornos naturales, culturales y sociales con la operación de estos centros; siendo 
los inversionistas privados y los responsables dentro de las instituciones estatales mexicanas que autorizan y regalan el territorio nacional los únicos que ganan (entrevistado por Mariel Massé, 2013).

Así, el "desarrollo turístico" se ha concentrado y sigue concentrándose exclusivamente en aspectos cuantitativos (número de camas y de visitantes), manteniendo la idea de un turismo a merced de las fuerzas del mercado (Altés, 2006). Además, los turistas no solo se adueñan del espacio sino que por su capacidad de compra son los únicos que pueden adquirir determinados servicios (agua, salud, educación, vías de acceso), y dejan a las poblaciones totalmente excluidas de esto (Cordero, 2006); es decir, el turismo depende del nivel económico (Arias, 2007), sin tener en cuenta el desarrollo local de los destinos receptores.

\section{El Estado y los megaproyectos turísticos}

El Estado es el centro del poder político de las relaciones entre las clases dominantes del capital. Asimismo es ejecutor de decisiones por medio del personal que labora en las instituciones que lo conforman, decisiones que muchas veces satisfacen los intereses de la burguesía. Con el neoliberalismo y la apertura del mercado la situación se agrava. En este caso, la nueva configuración estatal y el poder local se ponen en evidencia cuando, a cambio de beneficios económicos, permiten desarrollos turísticos a pesar de conocer los riesgos que conllevan y de tener plena conciencia de que estos incumplen la legislación ambiental nacional e internacional, autorizando la depredación en los espacios donde son planeados. Esto ha sido posible gracias a la presión de las prácticas neoliberales adoptadas por el Estado en favor de los intereses de las firmas trasnacionales y organizaciones mundiales que dirigen las políticas del turismo internacional y quienes tienen el poder económico-político para establecer relaciones con el personal dentro de los aparatos del Estado mexicano, lo que a su vez se ha traducido en un compromiso para cumplir las demandas extranjeras a cambio de préstamos e inversiones. Por tal razón, aunque la búsqueda de la sustentabilidad se integró a la normatividad nacional bajo un discurso de protección del patrimonio y al programa de áreas naturales protegidas (ANP) -como adaptación de 
un programa global propuesto también por los organismos internacionales-, se sigue operando un modelo turístico internacional con las prácticas que implica.

La hegemonía del turismo de masas surgió de un poder económico globalizado que sigue el mismo objetivo: la acumulación de capital a través de las relaciones de poder y explotación en un sistema interestatal en el que las clases que detentan el poder político tienen la capacidad de llevar a cabo megaproyectos para la continua reproducción de un modelo turístico capitalista. El personal dentro de las instituciones estatales -ya sean funcionarios o servidores públicos-pertenece a las clases dominantes y tiene la ventaja de conducir directamente el Estado de acuerdo con sus objetivos. También puede suceder que el personal no pertenezca a la clase dominante (clase reinante), pero sí busque crear relaciones de poder con los organismos internacionales.

Las instituciones estatales se comprometen al adoptar las políticas y condiciones que les determina el sistema mundial, comprometiendo al país a satisfacer las demandas del poder político y económico hegemónico. La clase reinante representa a los funcionarios y ejecutores de las políticas turísticas impuestas como intereses de toda la sociedad; protegiendo los fines de las élites trasnacionales y en segundo plano las necesidades y demandas de las clases populares [Osorio, 2014].

Entre las inmobiliarias turísticas y la nueva organización estatal mexicana existe un frente de poder que solo permite el autoritarismo del capital. En este caso, "el Estado actúa como transmisor y ejecutor de las decisiones de una élite” (Chomsky y Dietrich, 2004: 67), basado en una condensación de relaciones de poder, dominio, explotación y fuerza que atraviesan a la sociedad, por medio de una clase reinante cuyo fin es satisfacer un turismo masificado, someter y transformar el patrimonio natural consintiendo el flujo de inversiones extranjeras para la realización de semejantes construcciones que, sin respetar el entorno natural y social, favorezcan la llegada de turistas extranjeros. La especulación, el uso de recursos económicos federales y la privatización del territorio son algunos de los procesos con los que operan los megaproyectos turísticos.

"La política de acumulación por despojo incentivada en las últimas décadas sobre territorios de comunidades campesinas, para la apropiación de tierras u otros recursos naturales revalorizados indígenas" (Osorio, 2012: 69-70) lleva a las comunidades a vender sus tierras a costos muy bajos. Ante tal situación, 
el gobierno puede favorecer la pérdida del territorio o frenarla relativamente, al desarrollar políticas de compra de tierras para establecer, por ejemplo, parques nacionales o espacios de uso público. Pero elegido el territorio se busca integrarlo a la circulación internacional de mercancías y entonces comienza la lucha por la apropiación del espacio; aquel donde se expresan las distintas contradicciones sociales (Cordero, 2006). Esto no contribuye al desarrollo sostenible de las comunidades locales pero sí al crecimiento económico de un grupo minoritario: los dirigentes del modo de producción capitalista imperante.

El Fonatur y la Secretaría de Medio Ambiente y Recursos Naturales (Semarnat) -en cuanto aparatos del Estado basados en relaciones de poder-dominio con las clases dominantes de las inmobiliarias turístico-comerciales y los organismos económicos internacionales-, sistemáticamente han relegado los intereses de los pueblos por administrar sus recursos, no obstante poseer una ideología política de desarrollo sustentable. Con formas de apropiación y dominación cada vez más legales, incurren en una serie de ecocidios sin respeto a los espacios rurales costeros, abaratando o simplemente regalando el territorio a capitales extranjeros y avalando estudios de impacto deficientes, donde la lucha social se conecta de manera directa con el desarrollo de la actividad turística, al cuestionar determinados ejes de las políticas gubernamentales (Cordero, 2006). Esto es una falta clara al compromiso de sustentabilidad adoptado por México en distintos acuerdos internacionales y demuestra el poder de los consorcios inmobiliarios turísticos sobre las leyes, normas y reglamentos del Estado, debido al derecho y a la autoridad de los funcionarios para tomar decisiones que obedecen a la presión de las políticas, compromisos y deudas internacionales.

En entrevista, Exequiel Ezcurra ${ }^{1}$ señala tres importantes cuestiones al respecto: a) los megaproyectos turísticos en el mar Mediterráneo (específicamente en España) han demostrado total insostenibilidad y evidencian la crisis y la destrucción que hoy los aquejan; $b$ ) en México, los megaproyectos son propuestos por empresarios de compañías inmobiliarias turístico-comerciales y financiados de manera directa o indirecta por el gobierno federal mediante los impuestos que

${ }^{1}$ Entrevistado por Mariel Massé el 22 de diciembre de 2014. Con formación en biología y ecología, en la actualidad es director del Instituto para México y los Estados Unidos en la Universidad de Baja California Investigadores del Consejo Nacional de Ciencia y Tecnología; además fue presidente del Instituto Nacional de Ecología y director del Consejo Natural de Áreas Naturales Protegidas (Conanp). 
los habitantes pagan año con año a la Secretaría de Hacienda; c) se basan en la apropiación de los recursos naturales para un beneficio a corto plazo, sin considerar los estragos negativos que dejan a largo plazo, los cuales se reducen a una insostenibilidad no solo ambiental sino también social; afectando a los que menos tienen.

Con fundamento en lo anterior, se analizó específicamente un lugar que ha sido ofrecido por el Estado mexicano y que en varias ocasiones ha atraído a los capitales trasnacionales. Se describen las amenazas inmobiliarias que lo han puesto en riesgo, en particular un primer caso que llevó a la población local a enfrentar la traición de la institución estatal máxima encargada de su protección.

\section{Cabo Pulmo, Baja California Sur, México: una tentación trasnacional-estatal para la construcción de otro megaproyecto}

En primer lugar describiremos las virtudes del lugar objeto de estudio para comprender porqué las trasnacionales y el Estado mexicano están tan interesados en crear el megaproyecto turístico Cabo Cortés. Se trata de un sitio de conservación desde hace más de 20 años -por iniciativa de la propia comunidad-. En un principio, los pobladores vivían sobre todo de la pesca, pero con el tiempo vieron degradado su ecosistema y nació la preocupación por recuperar sus recursos terrestres y marítimos (arrecife y especies de fauna marina), de tal modo que hoy representa un patrimonio mundial de la humanidad.

Cabo Pulmo se localiza al norte del país, en el municipio de Los Cabos y al sur de la península de Baja California, entre el océano Pacífico, el mar de Cortés y el golfo de California. Está conectado por la carretera transpeninsular en su tramo La Paz-San José del Cabo, con un camino pavimentado hasta $10 \mathrm{~km}$ antes de Cabo Pulmo; después sigue un camino de terracería que conduce al parque.

Este lugar fue habitado por dos culturas de origen prehispánico: los palmas y los pericúes. De la primera se sabe que enfrentó un severo cambio climático, y la segunda, durante la llegada de los españoles, se asentó en las islas de Cerralvo, Espíritu Santo y Santa Fe. Las actividades predominantes de este pueblo fueron la recolección de frutos-semillas, la pesca (ballena, tortuga marina, mantarraya, anchoveta, cabrilla, mojarra, pez gallo, vieja, dorado, cohito, macarela, 


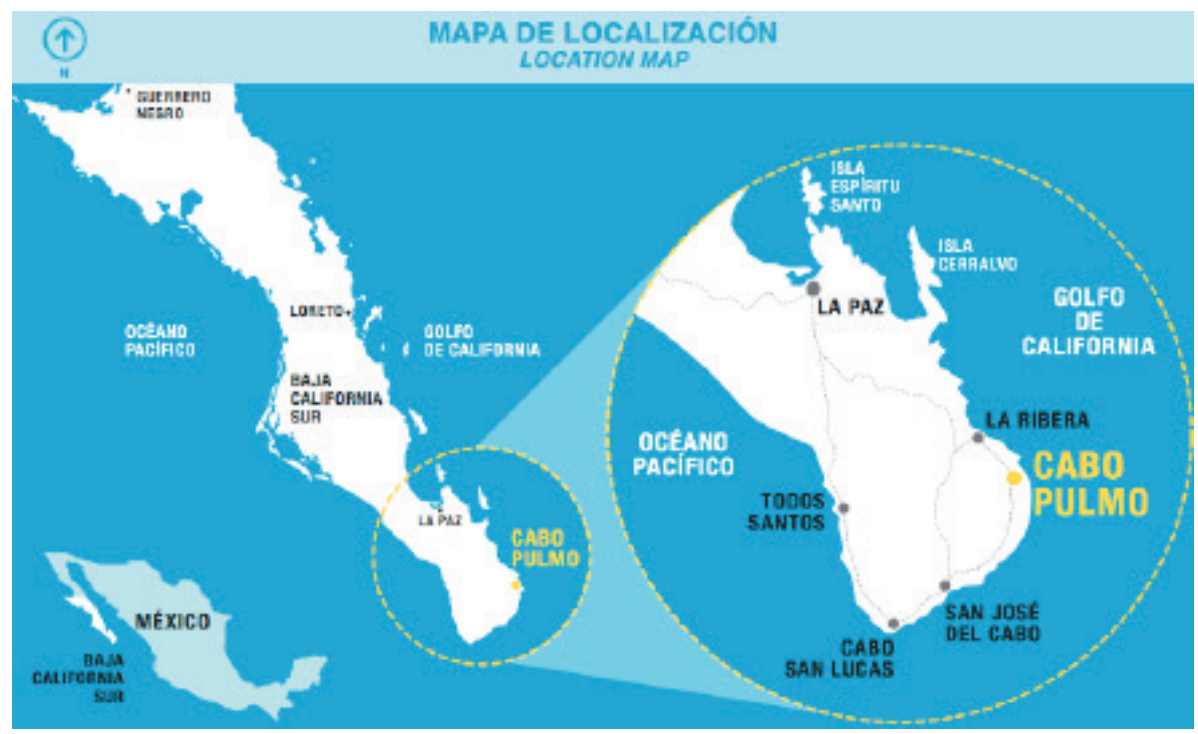

Fuente: http://cabopulmoamigos.org/donde-estamos.html [2015, 11 junio].

Figura 1. Mapa de localización

bagre, perico, lisa, pargo y sardina), la extracción de moluscos y la caza. Su estructura social estaba jerarquizada en: líderes de guerra, chamanes o médicosbrujos, hombres, mujeres adultas, ancianos y niños (Cariño et al., 2008: 75-80).

Desde el siglo xvi, la costa de Cabo Pulmo se caracterizó por ser rica en la extracción de perlas y nácar, por lo que durante el Porfiriato se impulsó una inversión privada extranjera. En este periodo destacaron cinco empresas perleras (González y Ruffo, Compañía Criadora de Concha y Perla de Baja California, La Perlífera del Golfo de Baja California, La Perlífera de San José y la Perlífera de Baja California), distinguidas por sus injusticias en el trato a su personal; por lo que los pescadores y armadores de la Paz pidieron al gobierno la cancelación de las concesiones territoriales, aunque esto no evitó el agotamiento de los recursos pesqueros (Cariño et al., 2008: 80-84).

El saber intergeneracional, que data de finales del siglo xix, relata que un francés llegó a este lugar enfermo de los pulmones y se curó con el consumo de la caguama (tortuga); por lo que se le otorgó el mote de "Cabo Pulmo". En ese momento la comunidad se conformaba por dos familias que se dedicaban 
exclusivamente a la pesca (perlas, tiburón, tortugas), la venta de quesos y carne. Después, una de estas familias creció y pobló la costa. La extracción de perlas se agotó pronto, así que optaron por exportar tiburón y tortuga. En la década de los sesenta aparecieron grupos de pesca clandestinos que acabaron con los recursos marinos. Hace 34 años la comunidad empezó a tener una visión conservacionista ante el arrecife, cambiando de forma positiva su aprovechamiento; aunque solo hasta la década de los noventa inició propiamente la búsqueda de su protección (Cariño et al., 2008: 84).

En 2009 se registraron en la localidad 20 familias, de las cuales solo 13 eran residentes y descendientes de los primeros habitantes de la zona. En la actualidad la población flotante está constituida por alrededor de 20 personas. A lo largo del año se registran turistas nacionales y algunos extranjeros cuya afluencia más marcada se da entre los meses de octubre a mayo. Distribuidas en un perímetro reducido con un promedio de 5.5 personas por cada vivienda, existen en total 17 viviendas de población local. También hay restaurantes, algunos bungalows y cabañas, que es la oferta reducida y de mediana escala para el turismo; estos servicios son administrados por la comunidad local de Cabo Pulmo y en menor medida por algunos propietarios extranjeros (Conanp, 2006).

Al ser entrevistado en 2014, Exequiel Ezcurra estableció que al percatarse de la degradación de los recursos marinos de la costa, la comunidad local decidió detener la actividad pesquera interna, externa y clandestina pensando en realizar una transformación en el uso de su patrimonio y en operar actividades de buceo y ecoturismo para evitar la pérdida total del ecosistema. Entonces, entre 1992 y 1993, los propios pobladores buscaron el apoyo de académicos, de Pronatura y de la universidad local, que desde 1986 empezó sus investigaciones en el lugar, para buscar legal y oficialmente la conservación de su territorio. Esta propuesta fue presentada al entonces encargado de la Semarnat, Luis Donaldo Colosio, para obtener del gobierno federal un decreto legal de conservación a nivel nacional para la costa de Cabo Pulmo, el cual se logró con éxito, pero fue expedido hasta 1995. De este modo, surgió a nivel federal el primer esfuerzo de protección de este gran espacio natural por medio de una declaratoria de protección como reserva marina y anp de México bajo la categoría de parque nacional (PN), con una superficie total de 7111 hectáreas. 


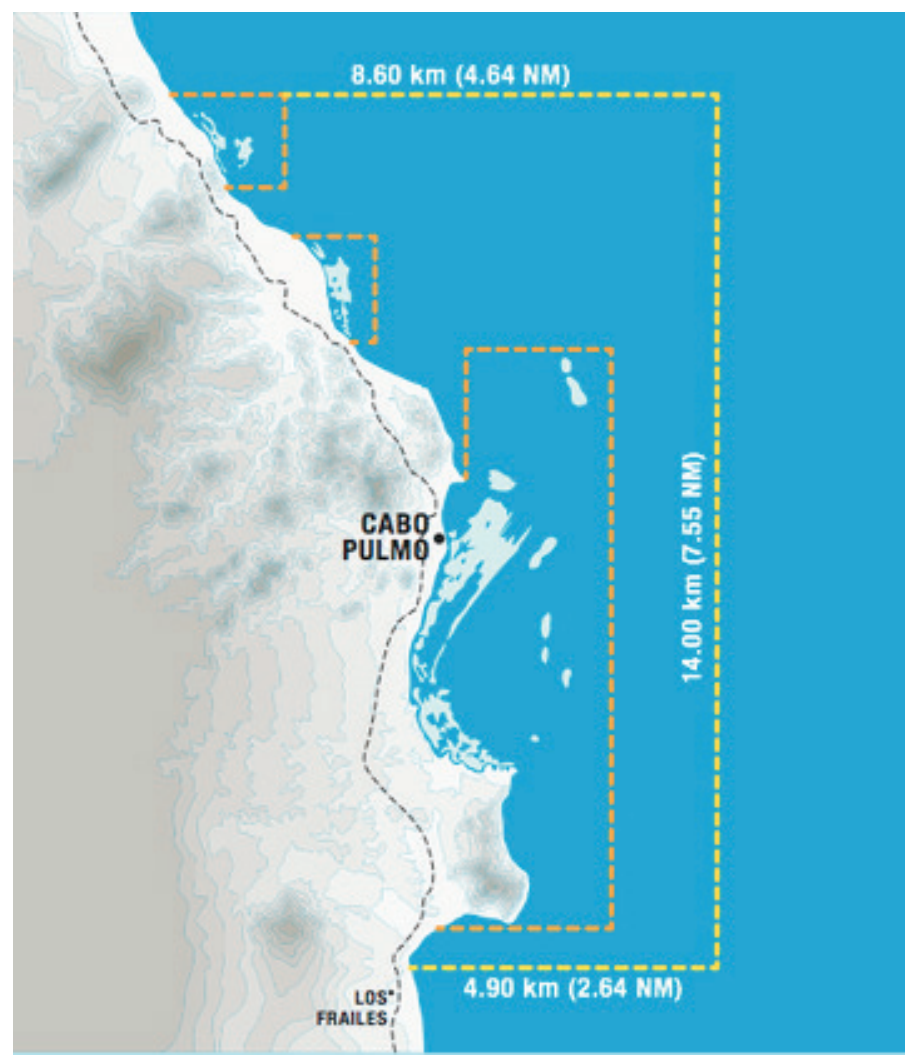

Fuente: http://cabopulmoamigos.org/el-parque.html [2015, 11 de junio].

Figura 2. Extensión del Parque Nacional Cabo Pulmo

Después del decreto nacional se han buscado otros reconocimientos de conservación a nivel internacional apoyados por ong, académicos e investigadores. Su relevancia hoy en día radica en algunas cualidades que aquí se describen:

- La anidación de tortugas marinas (cinco de las siete especies existentes en el mundo), incluida la golfina y la laúd (catalogadas en peligro de extinción y amenazadas, por lo que cuentan con medidas especiales de conservación). 
- Concentra el arrecife de coral más grande del golfo de California, con una antigüedad de 20000 años y quizás el más viejo del Pacífico americano.

- Es sitio de retorno de especies migratorias marinas (tiburón ballena, mantas gigantes, ballenas jorobadas, tortugas, leones marinos, delfines, entre otros) y terrestres, catalogadas en extinción o con algún programa de protección.

- Es el principal exportador del sector pesquero para Cabo del Este y el resto de Baja California Sur.

- Es uno de los principales destinos receptores de buceo y turismo de naturaleza en el mundo, y su derrama económica beneficia directamente a la comunidad local.

- Desde 20005 pertenece a la Lista de Patrimonio Mundial de la Humanidad bajo el nombre de Islas y Áreas Protegidas del Golfo de California, y desde 2008 también a la lista Ramsar de Conservación de Humedales de Importancia Internacional; estas denominaciones se lograron gracias al arduo esfuerzo de la población cabopulmense, apoyada por investigadores, académicos y ong involucrados desde su decreto como anp.

- Actualmente representa el sitio de mayor concentración de peces en el golfo de California.

- La creación de su propia ong: Amigos para la Conservación de Cabo Pulmo (АССР $),{ }^{2}$ en el año 2003, cuyos principios se basan en la conservación, la comunidad y la comunicación. Este organismo realiza programas de reciclaje, vigilancia comunitaria, monitoreo de calidad del agua marina y monitoreo de tortugas y del arrecife, también tiene un plan estratégico basado en fomentar el desarrollo armónico e integral de la comunidad, fortalecer la economía local y la industria del turismo y participar en la conservación del Parque Nacional Cabo Pulmo; en cuanto a la comunicación, elabora campañas, lleva a cabo acciones de cabildeo y de educación.

- En más de 20 años de conservación se pudo observar una recuperación de hasta 463 \% entre 1999-2009 (Aburto-Oropeza et al., 2011). 
Cabo Pulmo conforma hoy en día una pequeña comunidad de alrededor de 120 habitantes, quienes desde su creación como área de protección se dedican a sus empresas familiares turísticas: renta de bungalows, cabañas y tiendas prestadoras de servicios y actividades sustentables de ecoturismo, como buceo, kayak, esnórquel, paseos en bicicletas y caballos, pesca (exclusivamente para el consumo local); observación de flora y fauna; además de servicios de alimentación con cuatro restaurantes, hospedaje: un hotel en Los Frailes y una tienda de abarrotes; siempre orientados a mantener un esquema amigable con el ecosistema y su conservación. Todos estos servicios, que de manera global conforman la actividad turística en el destino, proveen los ingresos necesarios para la autosuficiencia y el abastecimiento de consumo para los residentes de la comunidad, ya que se distribuyen entre las familias que habitan en la costa. A pesar de estas actividades y servicios tan limitados, los ingresos obtenidos se quedan en manos de la comunidad. Los servicios básicos, como la corriente eléctrica y el gas, son ofrecidos por medio de paneles y calentadores solares. Por otra parte, el agua es un recurso escaso en Baja California Sur, debido a su ecosistema desértico; y, aunque se cuenta con este servicio, se pide a los visitantes un uso responsable del mismo.

En palabras de Exequiel Ezcurra, entrevistado por Mariel Maseé en 2014:

El manejo del parque a manos de los pobladores les ha permitido un nivel de vida estable, trayendo beneficios económicos y ambientales; por lo que consideran que los modelos de desarrollo turístico para esta zona deben ser totalmente sustentables y acordes a las capacidades y condiciones del lugar, es decir, como se ha venido manejando desde hace más de 20 años que inició su conservación. Sin embargo, la calidad paisajística del Parque Nacional Cabo Pulmo (PNCP) lo convierte en un espacio terrestre-marítimo vulnerable ante los intereses privados; lo que hace que su comunidad se muestre alerta ante cualquier propuesta de desarrollo turístico.

\section{El Estado y el megaproyecto turístico Cabo Cortés}

En 2008, la inmobiliaria española GRE Hansa Urbana Investments presentó a la Dirección General de Impacto y Riesgo Ambiental (DGIRA) de la Semarnat una 114 manifestación de impacto ambiental (MIA) para que le autorizara el megaproyecto turístico Cabo Cortés, que se ubicaría cerca del Parque Nacional Cabo 
Pulmo. La extensión del megacomplejo abarcaría entre 3814 y 4108 hectáreas, a lo largo de las cuales se construirían dos campos de golf de 27 hoyos cada uno, una desaladora, condominios, residencias unifamiliares, un pueblo de apoyo para los trabajadores, un aeropuerto, una marina para 490 posiciones y 15 hoteles con cerca de 30000 habitaciones entre cuartos y viviendas (dimensiones aproximadas, teniendo como referencia el cIP Cancún) (NRDC, 2012); de nuevo, infraestructura planeada para satisfacer la demanda de un turismo masificado.

En cuanto a sus características, Alejandro Olivera Bonilla ${ }^{3}$ destacó que resultaba totalmente incongruente proponer un desarrollo de tales magnitudes justo a un lado del parque y en una localidad muy pequeña; era algo fuera de la realidad ya que el proyecto así planteado traería graves afectaciones; incluso la sola idea de una desaladora, pues esta llevaría sus desechos al arrecife o tendría una concesión de agua de primer uso. Gladys Rodríguez Navarro ${ }^{4}$ coincidió en esto y agregó que se duplicaría la población actual, lo que agravaría la escasez de agua. A pesar de haber tenido indicios importantes de recuperación (Aburto-Oropeza et al., 2011), se demostraba una clara inviabilidad para la construcción de este megaresort con el triple de capacidad que soporta el municipio de Los Cabos. La trasnacional española, con intereses en un turismo de élite y bajo el discurso de mejorar la calidad de vida de las comunidades, ha participado en otras obras de infraestructura en México y cuenta con un historial de proyectos truncados por problemas financieros en las costas de España y la Caja de Ahorro del Mediterráneo (CAM), que resultó en la venta de sus acciones a esta última.

Exequiel Ezcurra, en la entrevista que se le hizo, precisó que no podía sino augurar otra vez un desastre natural y social como el que se ha visto en otros lugares: Acapulco, Cancún, La Paz (en Baja California), Loreto y Puerto Escondido, entre otros, pues el lugar tampoco cuenta con la capacidad para soportar un complejo de tal tamaño y demanda de recursos naturales; puntualizó que la empresa en ningún momento tuvo la intención de construir, porque se encontraba en quiebra debido al colapso inmobiliario que hubo en toda Europa (de

\footnotetext{
${ }^{3}$ Entrevistado por Mariel Massé el 4 de octubre de 2013. Ex coordinador de Océanos y Costas de Greenpeace y actualmente coordinador de Políticas Públicas del Centro Mexicano de Derecho Ambiental (Cemda)

${ }^{4}$ Entrevistada por Mariel Massé el 15 de octubre de 2013. Corresponsal del periódico El Universal. Participó en diversas notas periodísticas siguiendo de cerca lo que sucedía en Cabo Pulmo.
} 
manera señalada en España), por lo que buscaba solamente hacer negocio con las tierras obtenidas a través de la especulación y los subsidios del gobierno federal, ya que estas podían ser vendidas a otros capitales con una mayor plusvalía. En términos generales, esta es la forma en la que funciona la dinámica del modelo de sol y playa y los resorts turísticos hegemónicos en manos de intereses privados bajo políticas centralizadas, que venden una idea de desarrollo con el único fin de generar crecimiento económico. El Estado, que establece relación con los organismos internacionales económicos y turísticos, es dominado por un poder económico-político mundial y es condicionado por las políticas neoliberales y turísticas internacionales para integrarse como patrocinador directo en la creación de centros turísticos con infraestructura masiva.

Personal especializado en materia de medio ambiente perteneciente a la Conanp (organismo descentralizado de la Semarnat) ofreció un dictamen técnico de los impactos negativos que tendría la puesta en marcha de Cabo Cortés.

\section{Cuadro 1. Impactos ecológicos y sociales de Cabo Cortés}

TIPO DE IMPACTO

Ecológico

\section{DESCRIPCIÓN}

- Agravamiento de la escasez de agua al tener que proveer a 71000 habitantes, es decir, 2000 litros de agua al día.

- Aumento incontrolable de la demanda de pesca y, por lo tanto, la pérdida de especies protegidas.

- Erosión de las playas debido a la marina.

Afectación al arrecife y al ecosistema en general.

Social
- En 25 años se triplicaría la población actual de todo el municipio.

- La pérdida en la calidad de vida de la población actual, al no proveer la demanda necesaria de servicios públicos y vivienda.

- Una sobreoferta turística además de la ya existente en Baja California Sur.

- Posible pérdida de la zona arqueológica donde se estableció la cultura pericúe.

- Otros: desplazamiento de la comunidad local, desempleo, pobreza, marginación, migraciones, violencia, asentamientos irregulares, robos, drogadicción, alcoholismo. 
Por su parte, Ezcurra menciona también como efectos negativos una cuestionable imagen internacional de México en cuanto a la calidad ecológica de sus destinos turísticos; insostenibilidad ambiental y social, beneficios a corto plazo para los capitalistas y el personal dentro de los aparatos del Estado, la explotación y deficiente calidad de vida de las comunidades locales, la destrucción de los ecosistemas, amén de pobreza, marginación, desigualdades sociales y contaminación.

En este caso, la autorización hizo notar contradicciones marcadas entre el personal dentro de los aparatos del Estado mexicano (Fonatur y Semarnat) y las disposiciones que establecen algunos instrumentos legales (NRDC, 2012; Sánchez Castro, s.f.), que llevan a cuestionar la legitimidad en este proceso. Las refutaciones se exponen en el cuadro 2.

\section{Cuadro 2. Instrumentos legales, disposiciones y contradicciones presentadas}

INSTRUMENTO LEGAL

Programa de

Ordenamiento

Ecológico del

Municipio de los

Cabos (POEMLC)

Ley General de Equilibrio Ecológico y Protección al Ambiente (LGEEPA)

\section{DisPOSICIONES/CONTRADICCIÓN}

Los desarrollos turísticos deben asegurar su propio abastecimiento de agua. La Comisión Nacional del Agua (Conagua) dio permiso a los inversionistas para concesionar los únicos tres pozos existentes, de los cuales dos ya se encuentran sobreexplotados y el tercero representa el único manto acuífero para proveer el consumo necesario de la población actual (entrevista a Alejandro Olivera Bonilla en 2013).

No deberá permitirse ningún tipo de construcción en zona de dunas costeras a lo largo del litoral. La marina del resort fue autorizada para desarrollarse sobre un área de dunas, las cuales sirven para la protección contra huracanes (entrevista a Gladys Rodríguez Navarro en 2013).

Artículo 35: No es posible autorizar posibles daños a la flora o fauna catalogada como amenazada o en peligro de extinción. Durante la evaluación de impacto ambiental (EIA) la Semarnat está obligada a sujetarse "a lo que establezcan los ordenamientos [leyes y reglamentos ambientales], así como los programas de desarrollo urbano y de ordenamiento ecológico del territorio, las declaratorias de áreas naturales protegidas..." (Moguel y Burt, 2013: 10).

El artículo 36 obliga a los consultores a decir la verdad respecto a los resultados de la MIA, y que fueron obtenidos a través de las mejores técnicas y metodologías aplicadas por científicos del país, donde las medidas de prevención y mitigación sugeridas sean las más efectivas para atenuar los impactos ambientales. Lo cual no cumplió el Estado mexicano (Moguel y Burt, 2013: 8). 


\section{Cuadro 2. Instrumentos legales, disposiciones y contradicciones presentadas (continuación)}

INSTRUMENTO LEGAL

Declaración de Río (1994) y Ley General de Vida Silvestre (LGVS)

Decreto del Parque Marino Nacional Cabo Pulmo (Presidencia de la República, 1995)
DISPOSICIONES/CONTRADICCIÓN

Principio precautorio 15: "Cuando haya peligro de daño grave e irreversible, la falta de certeza científica o absoluta no deberá utilizarse como razón para postergar la adopción de medidas eficaces en función de los costos para impedir la degradación del medio ambiente".

Artículo 4: se permite la pesca con fines de consumo doméstico. Artículo 5: sólo se permitirán actividades relacionadas con la preservación.

Artículo 6: todo proyecto que pretenda ser realizado debe estar en congruencia con los lineamientos del Programa de Manejo y la LGEEPA. Artículo 7: queda prohibido verter o descargar contaminantes, desechos o cualquier otro tipo de material. El arrecife del parque corría riesgo con los sedimentos y desechos de salmueras que serían vertidos al mar por medio de la desaladora.

Ley Federal de Procedimiento Contencioso Administrativo Artículo 51: "se declarará que una resolución administrativa es ilegal cuando se demuestre alguna de las siguientes causales:

1. Incompetencia del funcionario que la haya dictado, ordenado o tramitado.

2. Omisión de los requisitos formales exigidos por las leyes."
Ley Federal de Procedimiento

Artículo 3: "son elementos y requisitos del acto administrativo:

[...]

III. Cumplir con la finalidad de interés público regulado por las normas en que se concreta, sin que puedan perseguirse otros fines distintos".

Falta de información verídica sobre las especies de flora y fauna existente, los impactos negativos y las medidas de mitigación, restauración y conservación.

- "Se originan corrientes en dirección Norte y de acuerdo con la disposición de las obras de toma y descarga no se presentarán problemas de recirculación de la salmuera" (Corporativo Aquacultura Profesional, 2008: 71). Está documentado que durante verano-otoño las corrientes dominantes van con dirección surnorte, mientras que durante invierno-primavera las corrientes van de norte a sur (Trasviña et al., 2012).

Olivera explica que los estudios de impacto ambiental pueden tener una alta o baja calidad, dependiendo de quién los realice o cuánto estén dispuestas a gastar las empresas en un estudio que cumpla todos los requisitos legales; por lo cual es más económico llegar a un acuerdo con los funcionarios (entrevista con Alejandro Olivera Bonilla en 2013). 
Cuadro 2. Instrumentos legales, disposiciones y contradicciones presentadas (finaliza)

\begin{tabular}{|c|c|}
\hline INSTRUMENTO LEGAL & DiSPOSICIONES/CONTRADICCIÓN \\
\hline $\begin{array}{l}\text { Opinión técnica } \\
\text { expedida por Conanp } \\
\text { y la Dirección General } \\
\text { de Política Ambiental } \\
\text { e Integración } \\
\text { Regional y Sectorial } \\
\text { (DGPAIRS) }\end{array}$ & $\begin{array}{l}\text { "No considera apropiada la realización de 'El proyecto' tal y como } \\
\text { se pretende ya que adolece de una visión integral y sustentable del } \\
\text { desarrollo del sur de BCS y en consecuencia del PNCP” (Conanp, 2009: } \\
\text { 29). La DGPAIRs también emitió una opinión negativa. }\end{array}$ \\
\hline Denuncias populares & $\begin{array}{l}\text { Denuncia contra la empresa española por la privatización de las } \\
\text { playas de Punta Arena, Tomates, los arroyos de Miramar y Tesos } \\
\text { (terrenos para el resort). } \\
\text { Por el incumplimiento de las condiciones ambientales respecto del } \\
\text { marco legal en materia ambiental: LGEEPA, POEMLc, Declaración de Río, } \\
\text { entre otras. }\end{array}$ \\
\hline
\end{tabular}

Fuente: elaboración propia con base en Presidencia de la República (1995), Conanp (2009), Moguel y Burt (2013), Valle (2009), Corporativo Aquacultura Profesional (2008) y Trasviña et al. (2012), y entrevistas a Alejandro Olivera Bonilla y Gladys Rodríguez Navarro en 2013.

Estos argumentos evidencian las contradicciones normativas que presentó el personal dentro de los aparatos de Estado y las clases dominantes de una firma trasnacional. De acuerdo con Ezcurra:

Inicialmente la obtención de tierras se dio a través del gobierno mexicano con Fonatur, donde su presidente en ese entonces, John McCarthy, recibió un millón de dólares de la misma empresa por los terrenos que les había regalado para la construcción del resort. Posteriormente Hansa Urbana le pagó al ex funcionario Raúl Arriaga para realizar los estudios de impacto ambiental correspondientes, a través de una consultora que él mismo puso en marcha después de haber fungido como subsecretario de Semarnat desde el gobierno de Vicente Fox. Finalmente la inmobiliaria obtuvo la autorización para la construcción del desarrollo turístico de manera agilizada gracias a Ricardo Juárez, quien fue relegado en la Secretaría por su ex colega Raúl Arriaga (entrevista, 2014).

Otras cuestiones consideradas agraviantes de acuerdo con la información obtenida en las entrevistas a los informantes clave son (cuadro 3): 
Cuadro 3. Opiniones de los informantes clave respecto de las faltas legales halladas en Cabo Cortés

\begin{tabular}{|c|c|}
\hline $\begin{array}{l}\text { INFORMANTE CLAVE } \\
\text { (SECTOR SOCIAL) }\end{array}$ & Argumentos \\
\hline Dr. Exequiel Ezcurra & $\begin{array}{l}\text { Hubo falsedad de información en los estudios de impacto } \\
\text { ambiental, además de que un consultor defendió con } \\
\text { mentiras los intereses de una empresa y ésta le pagó por } \\
\text { eso. } \\
\text { - Una empresa que quiere hacer las cosas bien no debería } \\
\text { pagarle a un ex funcionario para que agilice el papeleo. } \\
\text { la toma de decisiones por un tiempo suficientemente largo y } \\
\text { prudente para evitar un conflicto de interés. } \\
\text { Según la ley, un estudio de impacto ambiental es un } \\
\text { manifiesto que se presenta bajo protesta de decir la verdad. }\end{array}$ \\
\hline $\begin{array}{l}\text { M. en C. Alejandro } \\
\text { Olivera Bonilla }\end{array}$ & $\begin{array}{l}\text { Resulta incongruente que el mismo gobierno haya } \\
\text { autorizado una amenaza de tal contexto, siendo quien al } \\
\text { principio convenció a la comunidad local de Cabo Pulmo } \\
\text { para cambiar su actividad pesquera por el ecoturismo para } \\
\text { evitar y revertir el desgaste que ya se había provocado } \\
\text { dentro del arrecife. } \\
\text { La estructura de la plantilla y el organigrama dentro de la } \\
\text { Semarnat, en materia de impacto ambiental (es decir, el jefe } \\
\text { de la dgira) facilitó el otorgamiento de autorizaciones ya } \\
\text { que solo dependía de una persona. }\end{array}$ \\
\hline $\begin{array}{l}\text { Gladys Rodríguez } \\
\text { Navarro }\end{array}$ & $\begin{array}{l}\text { La Semarnat otorgó el doble de tiempo permitido a } \\
\text { la empresa para cumplir las condiciones necesarias } \\
\text { establecidas en la ley, lo que significó una doble } \\
\text { autorización: } 2008 \text { y } 2011 \text {. } \\
\text { Correos electrónicos que mostró la Secretaría de Economía } \\
\text { (se) a Greenpeace revelan permisos, acuerdos, estrategias } \\
\text { y pactos entre Rafael Elvira Quezada, como titular de } \\
\text { Semarnat, y Juan Rafael Galea, en representación de su } \\
\text { padre (Rafael Galea), como principal responsable de Hansa } \\
\text { Urbana Investments. }\end{array}$ \\
\hline
\end{tabular}

Fuente: Elaboración propia. 
Ante estos actos de devastación, que implican la desviación de las obligaciones de la función pública en la búsqueda de intereses privados e ilícitos, la implementación de un modelo turístico trasnacional que ha dejado graves afectaciones en otros lugares, la imposición de políticas centralizadas, el enriquecimiento privado y en general las amenazas que Cabo Cortés representaba, se identificó la urgencia de defender el patrimonio natural mediante la lucha social.

\section{La defensa de Cabo Pulmo: sociedad civil y ong}

Las políticas de acumulación por despojo que sustentan al capital han llevado a las comunidades locales y a la sociedad civil a manifestarse agresivamente, propiciando su organización, resistencia y lucha por sus intereses comunes (Osorio, 2012). La necesidad de observar la pérdida y degradación de los ecosistemas y de sus comunidades locales nace de la ambición de los capitales trasnacionales -que ya han consumido paisajes tanto en México como en otros países- que andan a la caza de un beneficio particular a costa de la sociedad civil y el ambiente natural. En este sentido, el Estado relegó los intereses y proyectos de la comunidad cabopulmense, la cual ha protegido el ecosistema donde habita mediante prácticas sustentables desde hace un par de décadas. Además, la importancia de Cabo Pulmo como fuente de vida, de desarrollo local y ejemplo mundial de conservación, gracias al arduo trabajo comunitario realizado desde la década de los noventa por recuperar su ecosistema, ha sido un factor fundamental para su defensa, aunque quizás el elemento más significativo fue el sentido de pertenencia de la comunidad respecto de su territorio, lo cual propició que se diera a conocer esta situación más allá del ámbito local.

La lucha social consistió en la participación de distintos actores; cada uno de ellos impulsó actividades específicas que fueron esenciales para evitar el desastre natural (cuadro 4). 
Cuadro 4. Actores sociales en la defensa de Cabo Pulmo

\begin{tabular}{|c|c|c|}
\hline ÁMBITO SOCIAL & NOMBRE & ACTIVIDADES REALIZADAS \\
\hline $\begin{array}{l}\text { Comunidad } \\
\text { local }\end{array}$ & $\begin{array}{l}\text { Amigos } \\
\text { para la } \\
\text { Conservación } \\
\text { de Cabo } \\
\text { Pulmo (AСCP) }\end{array}$ & $\begin{array}{l}\text { - Búsqueda de apoyo con la Universidad Autónoma de } \\
\text { Baja California Sur y ong nacionales e internacionales. } \\
\text { kayakividades sustentables dentro del parque: buceo, } \\
\text { Limpieza de las playas. } \\
\text { Campañas para la conservación de la tortuga marina, } \\
\text { monitoreo del arrecife y de la calidad del agua. }\end{array}$ \\
\hline & $\begin{array}{l}\text { Centro } \\
\text { Mexicano } \\
\text { de Derecho } \\
\text { Ambiental } \\
\text { (Cemda) }\end{array}$ & $\begin{array}{l}\text { Litigio ambiental a través de las autorizaciones } \\
\text { en materia de impacto ambiental por medio de } \\
\text { herramientas como: recurso de revisión, denuncias, } \\
\text { juicios de nulidad y comunicados de prensa. }\end{array}$ \\
\hline ONG & Greenpeace & $\begin{array}{l}\text { Jornadas, campañas de medios, marchas, } \\
\text { manifestaciones, reuniones, búsqueda de apoyo } \\
\text { de celebridades, más de } 220000 \text { firmas reunidas, } \\
\text { protestas, mesas informativas en diez entidades } \\
\text { federales, movimientos en las redes sociales e } \\
\text { internet. }\end{array}$ \\
\hline $\begin{array}{l}\text { Medios } \\
\text { periodísticos }\end{array}$ & $\begin{array}{l}\text { La Jornada } \\
\text { El Universal } \\
\text { Proceso } \\
\text { Sin Embargo }\end{array}$ & $\begin{array}{l}\text { Comunicados, conferencias de prensa en conjunto } \\
\text { con la comunidad local y las ong, notas constantes } \\
\text { en el seguimiento de la situación. }\end{array}$ \\
\hline $\begin{array}{l}\text { Académico, } \\
\text { científico }\end{array}$ & $\begin{array}{l}\text { Dr. Exequiel } \\
\text { Ezcurra }\end{array}$ & $\begin{array}{l}\text { Creación y publicación de información científica } \\
\text { útil para los opositores del megacomplejo acerca de } \\
\text { las afectaciones del proyecto, su inviabilidad y la } \\
\text { importancia de conservarlo. }\end{array}$ \\
\hline
\end{tabular}

Fuente: Elaboración propia con base en entrevistas a Exequiel Ezcurra en 2014, y Alejandro Olivera Bonilla y Gladys Rodríguez Navarro en 2013.

A pesar de que no se llevó a cabo el desarrollo de Cabo Cortés, el pNcP ha sido amenazado desde entonces por proyectos de similar magnitud que presentan distintas firmas internacionales turísticas apoyadas en las relaciones que han establecido con el personal del aparato del Estado mexicano, pero que siguen exigiendo una demanda de recursos naturales que excede las capacidades del 122 sitio previsto: 
Cuadro 5. Amenazas a Cabo Pulmo

\begin{tabular}{|c|c|c|c|c|}
\hline NombRe & Cabo Cortés I & CABo CoRTÉs II & Los Pericúes & Cabo Dorado \\
\hline $\begin{array}{l}\text { Año (ingreso y } \\
\text { cancelación) }\end{array}$ & 2008-2012 & $2011-2012$ & 2012 & 2014 \\
\hline Promovente & $\begin{array}{l}\text { Gre Hansa Baja } \\
\text { Investments } \\
\text { Méx. }\end{array}$ & $\begin{array}{l}\text { Gre Hansa } \\
\text { (España) }\end{array}$ & $\begin{array}{l}\text { OHL La Ribera } \\
\text { Desarrollos } \\
\text { (España) }\end{array}$ & $\begin{array}{l}\text { La Ribera } \\
\text { Desarrollos } \\
\text { (China) }\end{array}$ \\
\hline Habitaciones & 30694 & 30694 & 23400 & 22503 \\
\hline Marina (posiciones) & 490 & 490 & 300 & No \\
\hline Desaladora & Sí & Sí & Sí & No \\
\hline Terrenos & 3814 ha & 3814 ha & 3769 ha & 3370 ha \\
\hline Aeropista & Sí & Sí & Sí & Sí \\
\hline $\begin{array}{l}\text { Campos de golf } \\
\text { (hoyos) }\end{array}$ & $2(27)$ & 2 & $2(18)$ & 2 \\
\hline Agua & $\begin{array}{l}4.8 \text { millones } \\
{\text { de } \mathrm{m}^{3}}^{3}\end{array}$ & $\begin{array}{l}4.8 \text { millones } \\
{\text { de } \mathrm{m}^{3}}^{3}\end{array}$ & $\begin{array}{l}4.8 \text { millones } \\
{\text { de } \mathrm{m}^{3}}^{3}\end{array}$ & $\begin{array}{l}4.8 \text { millones } \\
\text { de } \mathrm{m}^{3}\end{array}$ \\
\hline $\begin{array}{l}\text { Cambio de uso } \\
\text { de suelo forestal } \\
\text { autorizado }\end{array}$ & Sí, 47 ha & Sí, 47 ha & Sí, 47 ha & Sí, 47 ha \\
\hline
\end{tabular}

Fuente: Cemda (2014).

Es importante mencionar que en la actualidad un tribunal colegiado resolvió un amparo en favor de Hansa Urbana, que obliga a la Semarnat a emitir un nuevo resolutivo para determinar si autoriza o no el proyecto Cabo Cortés II, ya que se encuentra vigente el cambio de uso de suelo y la constructora aún mantiene una concesión de la sct referente a la cimentación y operación de la marina (Cemda, 2014).

A pesar de vivir en un mundo globalizado, con políticas ajenas a los intereses públicos y la nueva configuración del Estado en favor de los capitales internacionales, Cabo Pulmo es ejemplo positivo de lo que una sociedad bien organizada puede lograr para su beneficio actual y futuro. 


\section{Conclusiones}

El poder económico y político que representa el capital relacionado con las clases reinantes del Estado mexicano, así como las políticas neoliberales y el mercado internacional turístico ayudan a explicar la situación turística de México. Al ser un país periférico y dependiente, ha sufrido una fuerte devastación medioambiental por la privatización de una de sus fuerzas productivas principales: el territorio. Así se han permitido (y se permiten) construcciones turísticas masivas cuyo fin es acumular capital en beneficio de quienes invierten y autorizan desde la organización estatal, es decir, funcionarios o ex funcionarios públicos. Estos últimos actúan para su provecho personal por medio de actos de poder económico, y modifican las leyes a conveniencia de los intereses privados, sin importar el desarrollo sustentable de las comunidades locales en la mejora de su calidad de vida ni la conservación del patrimonio natural.

Los principales aspectos de esta problemática son:

- El Estado autorizó, en un inicio, el megaproyecto turístico Cabo Cortés por medio de un creciente despliegue del aparato estatal y de sus instituciones, leyes, normas y la condensación de la red de relaciones de poder-dominio.

- La escasez de agua, el sentido de pertenencia de la comunidad local y el esfuerzo por conservar su territorio en coordinación con distintos sectores sociales (medios periodísticos, ong nacionales e internacionales, científicos-académicos-investigadores) permitieron la defensa de un ecosistema único en México y en el mundo.

- El megaproyecto de Cabo Cortés proviene de una política turística internacional creada por los dirigentes del mercado y la economía mundial, que por medio de la inversión pretenden ampliar sus ganancias a partir del modelo de sol y playa, cuya infraestructura se sustenta en 30000 cuartos de hotel, lo cual excede la capacidad de los recursos naturales de Cabo Pulmo.

- Los megaproyectos han provocado la pérdida del territorio y de los ecosistemas, así como la degradación de la vida de las comunidades donde son desarrollados, ya que los beneficios solo llegan a las firmas trasnacionales y al Estado, por lo que causan la resistencia social. 
- La corrupción del aparato estatal y la presión de los organismos internacionales (FMI, BM, BID, омт) que dominan el mercado mundial fueron determinantes para favorecer los intereses del capital internacional turístico (Hansa Baja Investments), a partir de una política neoliberal.

- La lucha social implica una gran acción por la defensa del medio natural; asimismo, cuestiona los planes de desarrollo, genera conciencia y lograr trascender y difundir estos casos más allá de los ámbitos de competencia jurídica nacional, apoyándose en oNG nacionales e internacionales, lo cual ha ayudado a evitar la destrucción de un ecosistema único en el mundo (entrevista a Gladys Rodríguez Navarro en 2013).

- Cabo Cortés es ejemplo de lo que permite la legislación mexicana actual. Por ello debe cambiarse la forma como se evalúan y aprueban los proyectos en relación con la Ley General del Equilibrio Ecológico y la Protección al Ambiente -la de mayor jerarquía en material medioambiental- y sus derivadas. Además es necesario evitar que la decisión de aprobar o desaprobar las autorizaciones en materia de impacto ambiental a cualquier plan de desarrollo turístico-comercial recaiga en una sola persona; debe tenerse en consideración la opinión de los principales afectados (la población local) y demás actores conocedores de los temas medioambientales y sociales (entrevista a Alejandro Olivera Bonilla en 2013).

- El modelo neoliberal vigente, aunado a la ideología capitalista del Estado, favorece los consumos de la industria turística de masas sin modificar las prácticas invasivas ante la diversidad de las formas de vida, gracias a una violencia administrativa que concesiona territorio y acepta desarrollos amenazadores.

- El modelo de industrialización de la actividad turística ayuda a entender cómo surgen las empresas capitalistas, en este caso las inmobiliarias turísticas, que buscan establecer construcciones masivas con base en un modelo tradicional, cuyo fin es captar la mayor cantidad de turistas posible y, con ello, divisas en zonas de playa, litorales o costas.

- Los inversionistas movidos por el afán de grandes ganancias monetarias guardan solo la moralidad y el racionalismo capitalista, manipulando o sobornando a consultores y funcionarios para que acepten las EIA y les autoricen sus megaproyectos. 
- El desplazamiento de los lugareños sigue vigente a causa del nepotismo de la clase política, que hace caso omiso del hambre de los propietarios -a quienes por sus recursos se les pagan cantidades irrisorias- y que, sin recato, abre la puerta a la destrucción de la naturaleza.

- El desplazamiento de las comunidades locales para crear los megaresorts sin tenerlas en cuenta para el desarrollo es causado porque las instancias gubernamentales pasan por alto su deber ser.

- Ante las faltas e irregularidades de la administración pública y la ambición del poder económico-político ha surgido una fuerte oposición de las comunidades afectadas y de ong, rechazo manifestado de distintas formas para exigir que el aparato estatal cumpla con su deber y se ocupe de defender el medio ambiente y su aprovechamiento sustentable.

- La capacidad de organización de la sociedad civil y el sentido de pertenencia de las poblaciones nativas respecto de su territorio son trascendentales para esta defensa.

- El periodismo crítico y el conocimiento científico apoyaron a las ONG, a la sociedad civil y a la comunidad cabopulmense con argumentos científicos para demostrar la inviabilidad del desarrollo.

- Las violaciones legales y omisiones a la normatividad halladas fueron, entre otras: el abastecimiento de agua, la prohibición de construcción en dunas, la descarga de residuos contaminantes hacia el arrecife, la afectación de especies en peligro o protegidas, los estudios de las corrientes.

- Se requiere continuar analizando los desarrollos promovidos y replantear los que ya existen, los cuales excluyen completamente a la sustentabilidad.

- De acuerdo con Gladys Rodríguez Navarro, hace falta que el Estado y los empresarios revisen la operatividad de la actividad turística en las costas mexicanas y que, con base en la evaluación, aprendan sobre los beneficios y los perjuicios causados al entorno natural y sociocultural; de este modo podrán integrar a la población local y decidir qué tipo de turismo es palanca de desarrollo. Rodríguez Navarro puso énfasis en que todo impulso turístico debe depender de las particularidades del entorno, pues esta consideración es la que permite elegir el modelo turístico más adecuado 
y orientado hacia la sustentabilidad y a la viabilidad, de acuerdo con las capacidades del territorio.

- De omitir las advertencias científicas de expertos sobre el caso de Cabo Pulmo y reabrir nuevamente la autorización a cabo Cortés o algún megaproyecto con las mismas características se pondría en riesgo total su ecosistema, se agravaría el desabasto de agua y se iría en detrimento de la calidad de vida de la comunidad local.

\section{Fuentes consultadas}

Aburto-Oropeza, O. et al. (2011). "Large Recovery of Fish Biomass in a No-Take Marine Reserve”. Plos One, 6 (8), 1-7.

Altés, C. (2006). El turismo en América Latina y el Caribe y la experiencia del BID [en línea]. Washington: Banco Interamericano de Desarrollo. Disponible en: http://services.iadb.org/wmsfiles/products/Publications/984876.pdf [2015, 7 de abril].

Arias, E. (2007). "Análisis del papel del turismo residencial en la cabecera municipal de Ixtapan de la Sal”. El Periplo Sustentable, 12, 5-42.

Bunge, V. (2011). "Ejercicio preliminar del impacto de la iniciativa de desarrollo turístico Cabo Cortés, B.C.S.” [en línea]. Documento de trabajo de la Dirección General de Ordenamiento Ecológico y Conservación de Ecosistemas. México: Instituto Nacional de Ecología. Disponible en: http://www.inecc.gob.mx/descargas/dgioece/doc_trabajo_cabo_cortes.pdf [2014, 14 de octubre].

Cariño, M. et al. (2008). "La creación del área natural protegida: actores, procesos y retos”, en A. E. Gámez (ed.). Turismo y sustentabilidad en Cabo Pulmo, B.C.S. San Diego: San Diego State University/Universidad de Baja California Sur/Consejo Nacional de Ciencia y Tecnología, 75-98.

Cemda (2014). "Revive Cabo Cortés, Cabo Pulmo de nuevo en riesgo" [en línea]. México: Centro Mexicano de Derecho Ambiental. Disponible en: http://www.cemda.org.mx/10/revive-cabo-cortes-cabo-pulmo-denuevo-en-riesgo/ [2014, 2 de diciembre].

Chomsky, N. y H. Dieterich (2004). La sociedad global. Educación, mercado y democracia. México: Planeta. 
Conanp (2006). Programa de Conservación y Manejo. Parque Nacional Cabo Pulmo. México [en línea]. México: Comisión Nacional de Áreas Naturales Protegidas. Disponible en: http://www.conanp.gob.mx/que_hacemos/pdf/programas_manejo/cabo.pdf [2015, 24 de junio]. (2009). “Opinión técnica presentada por la Conanp en relación al procedimiento de evaluación de impacto ambiental del proyecto Cabo Cortés, promovida por GRE Hansa Baja Investments, S.A. de C.V.” [en línea]. Disponible en: http://cabopulmovivo.org/portal/wp-content/ uploads/6OPINI-1.pdf [2014, 15 de octubre].

Cordero, A. (2006). Nuevos ejes de acumulación y naturaleza. El caso del turismo. Buenos Aires: Consejo Latinoamericano de Ciencias Sociales.

Corporativo Aquacultura Profesional (2008). miA-Regional Proyecto Cabo Cortés [en línea]. Disponible en: http://app1.semarnat.gob.mx/dgiraDocs/documentos/bcs/estudios/2008/03BS2008T0004.pdf [2015, 5 de mayo].

Greenpeace (2010). Cabo Cortés: destruyendo el paraíso [en línea]. Madrid y México: Greenpeace. Disponible en: http://www.greenpeace.org/ mexico/Global/mexico/report/2010/8/dossier_hansa.pdf_[2014, 21 de octubre].

Lanfant, M.-F. (1980). "Introducción: El turismo en el proceso de internacionalización”. Revista Internacional de Ciencias Sociales, 32 (1), 14-45.

Moguel, S. y S. Burt (2013). "Petición ciudadana presentada a la Comisión para la Cooperación Ambiental conforme al artículo 14, Acuerdo de Cooperación Ambiental de América del Norte. Incumplimiento de México de la legislación ambiental por autorizar mega resorts en el Golfo de California” [en línea]. Baja California Sur y San Francisco: Asociación Interamericana para la Defensa del Ambiente/Earth Justice. Disponible en: http://earthjustice.org/sites/default/files/PeticionCCAGolfodeCalifornia13-4-10.pdf [2014, 6 de noviembre].

NRDC (2012). "Hansa Urbana's Cabo Cortés Project in Baja California Sur: Investor Risk Advisory” [en línea]. Nueva York: The National Resources Defense Council. Disponible en: http://www.nrdc.org/international/ files/Baja\%20Investor\%20Briefing_11LR.pdf [2013, 5 de octubre].

Osorio, J. (2014). El Estado en el centro de la mundialización. La sociedad civil y el asunto del poder. México: Fondo de Cultura Económica/Universidad Autónoma Metropolitana-Xochimilco. 
(2012). Estado, biopoder y exclusión. Barcelona: Anthropos/Universidad Autónoma Metropolitana-Xochimilco.

Presidencia de la República (1995). "Decreto por el que se declara área natural protegida con el carácter de Parque Marino Nacional, la zona conocida como Cabo Pulmo, ubicada frente a las costas del Municipio de Los Cabos, B.C.S., con una superficie de 7,111-01-00 hectáreas” [en línea]. Diario Oficial de la Federación, 6 de junio, 3-5. Disponible en: http:// www.conanp.gob.mx/sig/decretos/parques/Cabopulmo.pdf [2014, 15 de octubre].

Sánchez Castro, M. A. (s.f.). "Argumentos legales por los que resulta inviable jurídicamente la autorización en materia de impacto ambiental del proyecto Cabo Cortés” [en línea]. México: Centro Mexicano de Derecho Ambiental. Disponible en: http://cabopulmovivo.org/portal/wp-content/uploads/8ARGUM-1.pdf [2014, 5 de octubre].

Trasviña, A. et al. (2012). "Observaciones de corrientes en el Parque Nacional de Cabo Pulmo, Baja California Sur: mediciones eulerianas en verano, otoño e inicios del invierno". Geos, 32 (2), 1-20.

Valle, E. (2009). "Recurso de revisión” [en línea]. Cabo Pulmo. Disponible en: http://cabopulmovivo.org/portal/wp-content/uploads/RRCABO-1.pdf [2014, 14 de octubre]. 
